\title{
Alternating hepatic arterial infusion and systemic chemotherapy for stage IV colorectal cancer with synchronous liver metastasis
}

\author{
MASAYA MUKAI $^{1}$, YASUHISA OIDA ${ }^{1}$, TAKAYUKI TAJIMA ${ }^{1}$, KYOKO KISHIMA ${ }^{1}$, HIROMI NINOMIYA ${ }^{2}$, \\ SHINKICHI SATO ${ }^{2}$, MASATO NAKAMURA $^{3}$, HISAO NAKASAKI ${ }^{4}$ and HIROYASU MAKUUCHI ${ }^{5}$ \\ ${ }^{1}$ Department of Surgery, Tokai University Hachioji Hospital, Ishikawa-cho 1838, Hachioji, Tokyo 192-0032; \\ ${ }^{2}$ Department of Pathology, Tokai University Oiso Hospital, Gakyou 21-1, Oiso, Kanagawa 259-0198; \\ ${ }^{3}$ Department of Pathology, Tokai University Hachioji Hospital, Ishikawa-cho 1838, Hachioji, Tokyo 192-0032; \\ ${ }^{4}$ Department of Surgery, Tokai University Oiso Hospital, Gakyou 21-1, Oiso, Kanagawa 259-0198; \\ ${ }^{5}$ Department of Surgery, Tokai University School of Medicine, Bohseidai, Isehara, Kanagawa 259-1193, Japan
}

Received June 30, 2006; Accepted July 28, 2006

\begin{abstract}
Among 41 patients with synchronous liver metastases of colorectal cancer, 15 patients underwent synchronous resection of their liver metastases and achieved a median survival time (MST) of 1,441 days (versus 748 days for the 26 patients without resection, $\mathrm{p}=0.038$ ), a median relapse-free survival time of 652 days (MST not reached), and a recurrence rate in the residual liver of $20 \%(3 / 15$ patients). The alternating hepatic arterial infusion and systemic chemotherapy showed partial response (PR) in 6 cases, stable disease (SD) in 8 cases, and progressive disease (PD) in 1 case $(n=15 / 26)$. They had an objective response rate of $40 \%(6 / 15)$, tumor control rate ( $\geq$ SD) of $93.3 \%$ $(14 / 15)$, one-year progression-free survival rate of $35.7 \%, 50 \%$ time to progression of 270 days, one-year survival rate of $76.2 \%$, and two-year survival rate of $50.8 \%$ (MST not reached). Grade 3 leucopenia was observed in $2 / 15$ patients $(13.3 \%)$. These results suggest that the present alternating therapy may become a standard regimen for patients in whom synchronous
\end{abstract}

Correspondence to: Dr Masaya Mukai, Tokai University Hachioji Hospital, Department of Surgery, Ishikawa-cho, Hachioji, Tokyo 192-0032, Japan

E-mail: mukai.masaya@hachioji-hosp.tokai.ac.jp

Abbreviations: MST, median survival time; OS, overall survival; RFS, relapse-free survival; PFS, progression-free survival; TTP, time to progression; TCR, tumor control rate; ONCs, occult neoplastic cells; 5-FU, 5-fluorouracil; LV, leucovorin; CPT-11, irinotecan; L-OHP, oxaliplatin; CDDP, cisplatin; TS, thymidilate synthase; DPD, dihydropyrimidine dehydrogenase

Key words: colorectal cancer, liver metastasis, hepatic arterial infusion, systemic chemotherapy, stage IV cancer, combined therapy resection of liver metastases is impossible and patients who have stage IV colorectal cancer with a risk of recurrence in the remnant liver and/or at extrahepatic sites such as the lungs.

\section{Introduction}

In the 1990s, the leading cause of cancer death in Japan was gastric cancer by a wide margin. However, with the recent westernization of eating habits and the lifestyle, gastric cancer has been replaced by lung cancer followed by liver and colorectal cancer in men (1). Similarly, gastric cancer was replaced by colorectal cancer as the leading cause of cancer death for women in 2005, followed by lung and breast cancer (1). The presence/absence of lymph node metastasis is known to be the most important prognostic indicator for gastrointestinal malignancies, including gastric and colorectal cancer, as well as for thoracic malignancies such as lung and breast cancer (2-5). Unlike other gastrointestinal malignancies, including gastric cancer, surgery is still indicated for colorectal cancer even when it has metastasized to distant organs such as the liver and lungs $(6,7)$. It is also known that colorectal cancer may cause fatal metastasis/recurrence in the liver or lungs after curative resection of the primary tumor, probably because free cancer cells circulate during the perioperative period and survive to proliferate in a distant organ after escaping from the immune system (8-11). Many investigators have reported that cytokeratin-positive occult neoplastic cells (ONCs), which represent circulating cancer cells, in lymph node sinuses distant from the primary tumor are closely related to the distant metastasis/recurrence of cancer (12-19). ONCs can be counted by immunostaining and represent floating malignant cells that have been trapped by the lymph nodes (8-11). ONC clusters ( $<10$ cells) formed by a number of floating ONCs or malignant micro-aggregates ( $\geq 10$ cells) can induce the metastasis/recurrence of cancer in distant organs after being released from the primary tumor. Therefore, it has been proposed that these cells should be 
distinguished from isolated tumor cells (ITCs) or micrometastases anchored in lymph nodes and should be recognized as more malignant occult systemic metastases (20). When metastases occur in the liver or lungs, surgical resection may still be indicated and many survivors have been reported. It is possible that metastatic foci arising from ONCs circulating in the perioperative period may be relatively localized tumors with a weak proliferative activity (20). In the Japanese Rules for Handling Colorectal Cancer, metastases to the liver or lungs are classified as synchronous when detected by imaging less than 12 months after resection of the primary tumor, and are considered to be metachronous when detected after one year or more (21). Since the TNM classification only specifies the presence/absence of distant metastases at the time of surgery, the Japanese clinical classification is more complicated (22).

Although many new chemotherapy agents have been developed recently, none has proved much more effective for colorectal cancer than the existing drugs. Therefore, investigators have come to focus on the concept of biochemical modulation, which suggests that anticancer agents should be combined with other drugs to increase efficacy and reduce adverse reactions $(23,24)$. 5-Fluorouracil $(5$-FU) exerts its antitumor effect through several mechanisms, including interference with DNA synthesis. An active metabolite (FdUMP) of 5-FU combines with 5,10-methylene tetrahydrofolate, which is a reduced form of folate, and thymidylate synthase (TS) to form a ternary complex, thereby blocking DNA synthesis and repair $(25,26)$. Thus, $5-\mathrm{FU}+$ leucovorin (LV) therapy is based on the concept that a certain level of reduced folate in the extracellular fluid is necessary to increase the antitumor activity of 5-FU. Multi-agent regimens, such as FOLFILI/FOLFOX/IFL, are based on new anticancer drugs such as Irinotecan (CPT-11) and oxaliplatin (L-OHP), and have been reported to be effective for advanced colorectal cancer (27-30). It has also been reported that combining hepatic artery infusion with systemic chemotherapy achieves a higher two-year survival rate than chemotherapy alone in patients who have undergone resection of liver metastases of colorectal cancer (31).

However, no effective combined therapy has been reported for patients with stage IV colorectal cancer in whom synchronous resection of multiple liver metastases cannot be performed. The present study was designed to examine the value of alternating hepatic arterial infusion and systemic chemotherapy for patients who had primary colorectal cancer with or without synchronously resectable liver metastases.

\section{Patients and methods}

Among 49 patients with synchronous liver metastasis (less than one year after surgery for the primary tumor) of stage IV colorectal cancer from January 2001 to January 2006, 41 patients meeting the following criteria were studied: 1) an age of $<75$ years, 2) a performance status of 0 or 1 (Japan Clinical Oncology Group; JCOG), and 3) complete medical records and follow-up data on recurrence and survival. The 41 patients were divided into 15 patients who underwent surgical resection of measurable or evaluable synchronous liver metastases, and 26 patients in whom synchronous resection of liver metastases could not be performed.

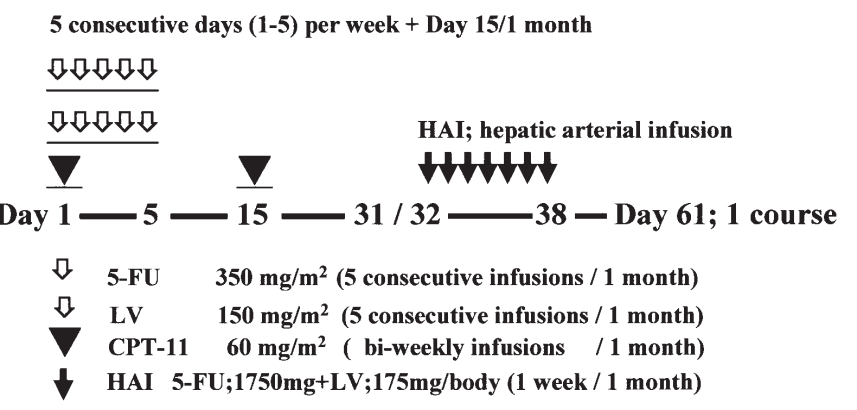

Figure 1. Schedule for alternating hepatic arterial infusion and systemic chemotherapy in stage IV colorectal cancer patients with synchronous liver metastasis.

Hepatectomy group. Surgery was indicated for 15 patients who underwent surgical resection of liver metastases including seven patients treated during surgery for the primary tumor with three or fewer liver metastases and a maximum tumor diameter of $5 \mathrm{~cm}$. These criteria were modified from those for $\mathrm{H} 1$ cases as specified in the Japanese Rules for Handling Colorectal Cancer, 7th version (fewer than five metastatic lesions and a maximum tumor diameter of $5 \mathrm{~cm}$ ) (21). Liver resection involved partial hepatectomy and/or enucleation of the tumors. After it was confirmed that the surgical margins were clear, alternating hepatic arterial infusion therapy and systemic chemotherapy were performed in 9 patients, while systemic chemotherapy alone was given to 6 patients. Hepatic arterial infusion therapy involved the administration of 1,750 mg of 5-FU and $175 \mathrm{mg}$ of LV over 1 week per month. Systemic chemotherapy was given with the modified IFL regimen $\left(5-\mathrm{FU} / \mathrm{LV}+\mathrm{CPT}-11: 350 \mathrm{mg} / \mathrm{m}^{2}\right.$ of $5-\mathrm{FU}+150 \mathrm{mg} /$ $\mathrm{m}^{2}$ of $\mathrm{LV}$ on five consecutive days per month $+60 \mathrm{mg} / \mathrm{m}^{2}$ of CPT-11 every fortnight) in 11 patients, while 5-FU/LV therapy was given to 4 patients $\left(350 \mathrm{mg} / \mathrm{m}^{2}\right.$ of $5-\mathrm{FU}+150 \mathrm{mg} /$ $\mathrm{m}^{2}$ of LV on five consecutive days per month). Chemotherapy was continued for at least three courses (Fig. 1) $(27,28,31)$. The other 26 patients without hepatectomy were used as controls. The overall survival (OS) rate and the median survival time (MST) were compared between the two groups. The recurrence rate in the remnant liver, median relapse-free survival (RFS) time, and MST for the residual liver were also calculated.

Non-hepatectomy group. Among 26 patients who did not fit the above indications for surgery from January 2004 to January 2006, 15 patients in whom liver resection was found to be impossible at the time of surgery for the primary tumor had measurable or evaluable synchronous multiple liver metastases that were unresectable and did not receive prior treatment such as radiotherapy or systemic chemotherapy. All 15 patients received alternating hepatic arterial infusion therapy and systemic chemotherapy over a two-month period per course. The modified IFL regimen was completely used for this alternating therapy and at least three courses were given over six months. The following parameters were investigated: the median number of courses, response rate (RR), tumor control rate (TCR $\geq$ stable disease; $\mathrm{SD}$ ), one-year progressionfree survival (PFS) rate, $50 \%$ time to progression (TTP), oneyear and two-year overall survival rates, and adverse events 


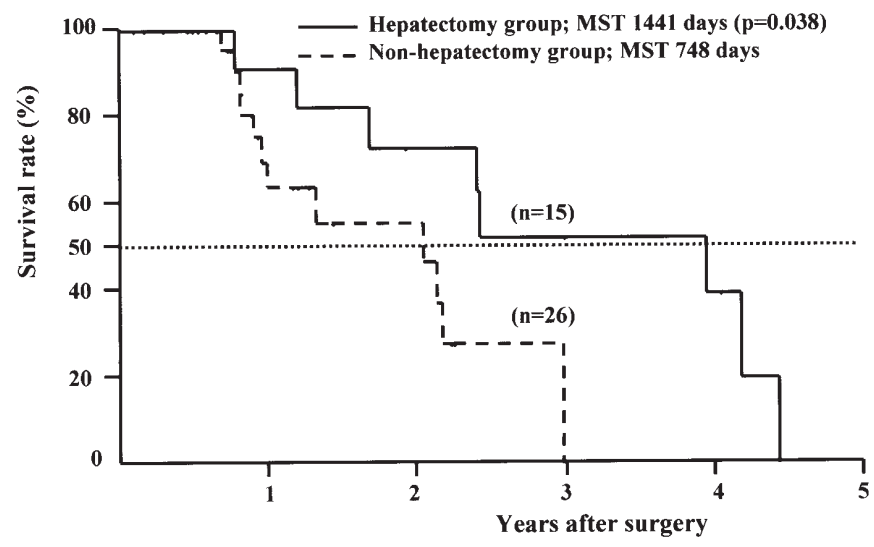

Figure 2. The median survival time (MST) of the 15 patients with resectable synchronous liver metastases was 1,441 days, while the MST of the 26 patients with unresectable synchronous liver metastases (control group) was 748 days $(\mathrm{p}=0.038)$.

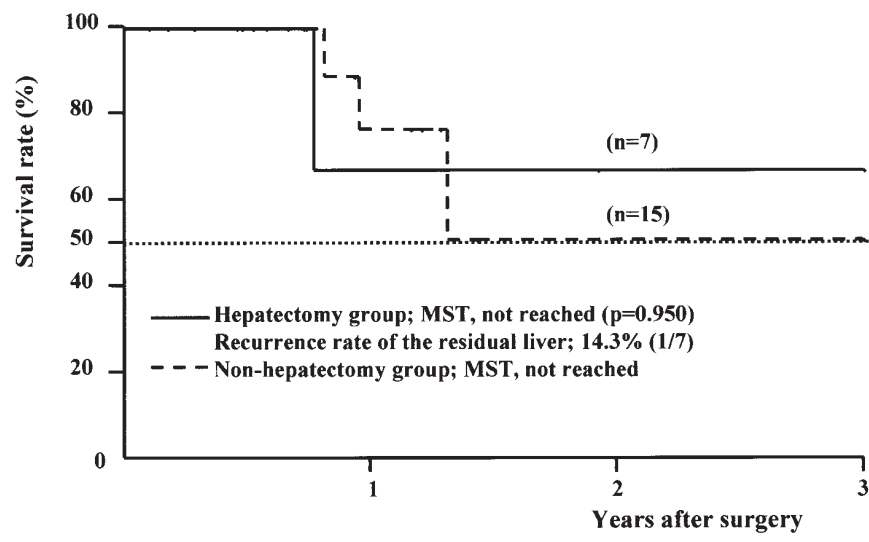

Figure 3. Among the seven patients who underwent resection of liver metastases during surgery on the primary tumor, the recurrence rate in the residual liver was $14.3 \%$ (1/7) (MST not reached). The MST was also not reached for 15 patients with liver metastases that were unresectable at the time of surgery on the primary tumor $(\mathrm{p}=0.950)$.

(Cytotoxic Criteria of the National Cancer Institute, version 2.0).

Statistical analysis. The OS rate, RFS rate, and TTP were calculated by the Kaplan-Meier method and the log-rank test was used for comparison between the hepatectomy and nonhepatectomy groups. A p-value of $<0.05$ was considered to indicate a significant difference in all analyses, which were done with SPSS 13.0 J software (SPSS Japan, Inc., Tokyo, Japan).

\section{Results}

Among the 15 patients who underwent resection of synchronous liver metastases, nine had multiple metastases (3 tumors in 2 patients and 2 tumors in 7 patients) and six had a solitary hepatic lesion. The MST of the 15 patients was 1,441 days, while the MST of the 26 patients with unresectable liver metastases (control group) was 748 days $(\mathrm{p}=0.038)$
Table I. Maximum anti-tumor effect (RECIST).

\begin{tabular}{lcccccc}
\hline Cases & CR & PR & SD & PD & NE & Response rate \\
\hline 15 & 0 & 6 & 8 & 1 & 0 & $40 \%$ \\
\hline
\end{tabular}

95\% C.I., 15.2-64.8\%; tumor control rate $\geq \mathrm{SD}$; $93.3 \%(14 / 15)$. Total administration courses, 68 courses; median value, 4 courses (2-11 courses).

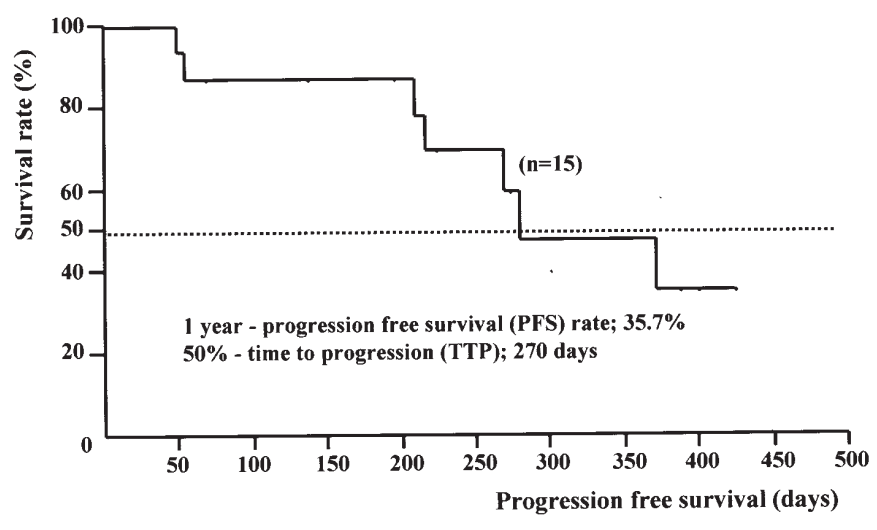

Figure 4. In 15 patients with unresectable synchronous liver metastases at the time of surgery for the primary tumor, the one-year progression-free survival (PFS) rate was $35.7 \%$ and $50 \%$ time to progression (TTP) was 270 days.

(Fig. 2). The median RFS time for the residual liver after hepatectomy was 652 days (MST not reached) and the recurrence rate in the residual liver was $20 \%$ (3/15). Among the seven patients who underwent resection of liver metastases during surgery on the primary tumor, six patients $(85.7 \%)$ received at least three courses of alternating hepatic arterial infusion and systemic chemotherapy. The recurrence rate in the residual liver was $14.3 \%$ (1/7) (MST not reached) (Fig. 3). The MST was also not reached for 15 patients with synchronous liver metastases that were unresectable at the time of surgery on the primary tumor ( $\mathrm{p}=0.950)$ (Fig. 3).

A total of 68 courses of alternating therapy were given and the median number of courses per patient was 4 (range: 2-11). The results obtained with alternating therapy did not include any complete responses (CR), but a partial response (PR) was achieved in 6 patients, stable disease (SD) was obtained in 8 patients, and progressive disease (PD) only occurred in one patient (Table I). None of the patients was classified as not evaluable (NE). The objective response rate (RR) was $40 \%(6 / 15)$ and the TCR was $93.3 \%(14 / 15)$ (Table I), while the one-year PFS rate was $35.7 \%$ and $50 \%$ TTP was 270 days (Fig. 4). The one-year and two-year survival rates were $76.2 \%$ and $50.8 \%$ (MST not reached), respectively (Fig. 5). The adverse events were grade 1 or 2 alopecia in $5 / 15$ patients $(33.3 \%)$, grade 3 leucopenia in $2 / 15$ patients $(13.3 \%)$, and grade 3 nausea/vomiting, appetite loss, and general fatigue in 1 patient $(6.7 \%)$ each. There were no grade 4 adverse events (Table II). 


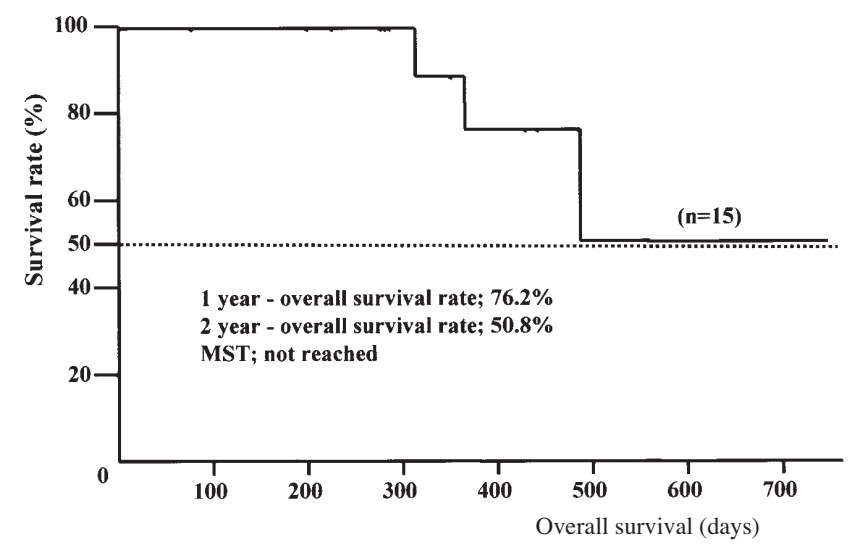

Figure 5. In 15 patients with unresectable synchronous liver metastases at the time of surgery on the primary tumor, the one-year and two-year survival rates were $76.2 \%$ and $50.8 \%$ (MST not reached), respectively.

\section{Discussion}

Based on the theoretical role of ONCs in metastasis/recurrence, it is necessary to eradicate ONC clusters released from the primary tumor that reach the liver and start to proliferate in the new microenvironment before these become occult metastases. Intensive consolidation chemotherapy should be most effective for this purpose. Arterial infusion therapy targeting the whole liver is essential for maintaining local control, even after the resection of liver metastases. The most frequent cause of death among the 15 patients who underwent resection of liver metastases was respiratory failure caused by severe pulmonary metastases $(n=4)$, followed by hepatic failure $(n=3)$, and then peritoneal dissemination, lymph node recurrence in the pelvic cavity, and another disease in one patient each (data not shown). Therefore, systemic chemotherapy is essential irrespective of whether or not patients have pulmonary metastases, considering that liver metastases may also release ONCs that could reach the lungs to cause fatal metastatic lesions (20). Previous examination of the sensitivity of ONCs to systemic 5-FU + LV therapy showed that few tumor cells displayed a high sensitivity (high TS/low DPD expression) in the recurrence group, suggesting that the chemotherapy regimens used currently might be inadequate (32-34). It has been reported that combination chemotherapy with CPT-11 and L-OHP, drugs which are more popular in Western countries than Japan, is clinically and pharmacokinetically more effective than 5-FU + LV therapy (27-30). Although the optimum administration regimen and dosage are important, the sensitivity of a tumor to additional anticancer agents is the main consideration. In the present study, we employed modified IFL therapy, in which CPT-11 (at a dose of $60 \mathrm{mg} / \mathrm{m}^{2}$ over one hour every 2 weeks) was added to hepatic arterial infusion and systemic 5-FU/LV therapy given five days a week on an outpatient basis. There were few dropouts until the second course irrespective of the resection of liver metastases. The dose of CPT-11 used in this regimen was much lower than the standard dose. However, even the modified IFL regimen designed for Japanese patients who are smaller than Europeans caused alopecia in 5 out of 15 patients (33.3\%) and grade 3 leucopenia in 2 patients, one of whom was treated
Table II. Adverse events for alternating therapy.

\begin{tabular}{llllll}
\hline Grade & 1 & 2 & 3 & 4 & Grade 3 \\
\hline Leucopenia & 2 & 3 & 2 & 0 & $2(13.3 \%)$ \\
Anemia & 2 & 1 & 0 & 0 & 0 \\
Thrombocytopenia & 0 & 0 & 0 & 0 & 0 \\
T. bil elevation & 1 & 0 & 0 & 0 & 0 \\
AST elevation & 2 & 1 & 0 & 0 & 0 \\
ALT elevation & 2 & 1 & 0 & 0 & 0 \\
Nausea/vomiting & 2 & 2 & 1 & 0 & $1(6.7 \%)$ \\
Appetite loss & 5 & 2 & 1 & 0 & $1(6.7 \%)$ \\
Diarrhea & 3 & 2 & 0 & 0 & 0 \\
General fatigue & 4 & 3 & 1 & 0 & $1(6.7 \%)$ \\
Pigmentation & 2 & 1 & 0 & 0 & 0 \\
Mucositis & 2 & 0 & 0 & 0 & 0 \\
Alopecia & 4 & 1 & 0 & 0 & 0 \\
Taste abnormality & 2 & 0 & 0 & 0 & 0 \\
\hline
\end{tabular}

with G-CSF and showed an increase of the white blood cell count to $>3,000 \mathrm{~m}^{3}$ during the next course. Hepatic arterial infusion achieved a local control rate $\geq 30 \%$, while intravenous FOLFILI/FOLFOX/IFL regimens were reported to achieve an RR of $30-35 \%$ (27-31). The present combination of alternating hepatic arterial infusion and systemic chemotherapy achieved an RR of $40 \%$, indicating an additive effect of only $\sim 10 \%$ for the combined regimen. However, since the TCR was $93.3 \%$ and SD was achieved in $53.3 \%$, the regimen was considered to be sufficiently effective for use as tumor dormancy therapy in stage IV patients. Administration of L-OHP is now covered by the Japanese national health insurance scheme in patients with advanced recurrent colorectal cancer that is not indicated for curative resection. However, this treatment still places a heavy economic burden on patients because short-term hospitalization is required every month. Recent studies have indicated that L-OHP often causes neurological symptoms, such as numbness of the fingers and lips, and many patients have discontinued it due to such adverse events (27-29). Despite such problems, the drug sensitivity profile of ONCs suggest that the addition of CPT-11 or L-OHP may have a synergistic effect. The value of these anticancer drugs for combination therapy is currently being investigated.

Colorectal cancer differs from gastric cancer with regard to the mode of metastasis/recurrence and its basic biological behavior. Even if colorectal cancer causes metastasis/ recurrence in a distant organ such as the liver or lungs, volume reduction surgery is indicated when the metastatic tumor is a solitary nodule or there is only two to three resectable lesions, and it is known that surgery achieves relatively good survival $(6,7)$. Unlike the TNM classification, the Japanese Rules for Handling Colorectal cancer define metastasis as synchronous when it develops within 12 months after resection of the primary tumor and as metachronous when it develops one year or more after resection. Regarding the theory of metastasis/recurrence from ONCs, clusters of these 
cells are released in the perioperative period and form micrometastases in the liver or lungs that contain at least 10 cells and have a longer axis $\geq 0.2 \mathrm{~mm}$ (20). Assuming that the minimum detectable lesion size by imaging methods such as ultrasonography and CT is $\geq 8 \mathrm{~mm}$, a lesion consisting of about 40 such cell clusters can be detected. Although occult metastatic lesions are often relatively localized with weak proliferative activity, the period of one year postoperatively in the Japanese definition of synchronous metastasis is considered too long. During the first postoperative year, oral anticancer drugs are often administered to stage II patients as postoperative adjuvant therapy, while first-line systemic chemotherapy is generally given to stage III patients and stage IV patients with N3 lymph node metastasis. Systemic chemotherapy is also used as second-line chemotherapy when patients are treated for metachronous liver metastases after surgery for stage III colorectal cancer, irrespective of the resection/non-resection of liver tumors. When patients with metachronous distant metastasis/recurrence are investigated, survival is often analyzed by using the overall survival rate because they are treated with various regimens. However, the clinical background may be biased because one year is automatically added to their survival compared with patients who have synchronous liver metastases. When the patients in whom resection or non-resection of metastases was decided at the time of surgery for the primary tumor were examined, no significant difference was noted between patients who underwent resection of liver metastases and those who did not, although the number of patients in each group was small. The survival prolongation of the non-resection group might be interpreted as indicating both local inhibition and systemic control of recurrence by alternating therapy, although the follow-up period was not adequate. Since the MST was not reached in the patients with unresectable liver metastases, it is possible that sufficient tumor dormancy may have been obtained, but it will be necessary to examine this issue in more subjects.

The maximum survival benefit is obtained by improving the survival rate of patients who suffer from recurrence $(35,36)$. However, it is quite difficult to evaluate the effect of therapy on recurrent tumors because treatment involves various modalities, including surgical resection, chemotherapy, chemoradiotherapy, and hepatic arterial infusion. In the present study, high one-year and two-year survival rates $(76.2 \%$ and $50.8 \%$, respectively) were obtained in patients who had previously untreated stage IV colorectal cancer with synchronous unresectable multiple liver metastases. In the future, a new combination regimen based on hepatic artery infusion plus systemic chemotherapy and molecular-targeting drugs may be developed to achieve a higher RR, and it is also hoped that the national health insurance system will be revised to cover more of the cost of combination therapy.

\section{Acknowledgements}

This study was supported by grants from the Occult Neoplastic Cells Research and Study Group (No. 2006-2291; Tokai University Hachioji Hospital, Hachioji, Tokyo, Japan) and the Research and Study Program of Tokai University Educational System General Research Organization (No. 2005-31; Tokai University Hospital, Isehara, Kanagawa, Japan).

\section{References}

1. Journal of Health and Welfare Statistics, Health and Welfare Statistics Association, Tokyo, 52: 45-47, 2005.

2. Omejc M, Juvan R, Jelenc F and Repse S: Lymph node metastases in gastric cancer: correlation between new and old UICC TNM classification. Int Surg 86: 14-19, 2001.

3. Goldhirsch A, Glick JH, Gelber RD, Coates AS and Senn H-J: Meeting highlights: International consensus panel on the treatment of primary breast cancer. J Clin Oncol 19: 3817-3827, 2001.

4. Multi-Institutional Registry of Large Bowel Cancer in Japan, Vol. 23, Cases treated in 1994. Japanese Society for Cancer of the Colon and Rectum, Tokyo, 2002.

5. Prenzel KL, Mönig SP, Sinning JM, Baldus SE, Brochhagen H-G, Schneider PM and Hölscher AH: Lymph node size and metastatic infiltration in non-small cell lung cancer. Chest 123: 463-467, 2003.

6. Galandiuk S, Wieand HS, Moertel CG, Cha SS, Fitzgibbons RJ, Pemberton JH and Wolff BG: Pattern of recurrence after curative resection of carcinoma of the colon and rectum. Surg Gynecol Obst 174: 27-32, 1992

7. Ambiru S, Miyazaki M, Ito H, Nakagawa K, Shimizu H, Kato A, Nakamura S, Omoto $\mathrm{H}$ and Nakajima N: Resection of hepatic and pulmonary metastases in patients with colorectal carcinoma. Cancer 82: 274-278, 1998.

8. Mukai M, Sato S, Komatsu N, Nishida T, Shiba K, Ito I, Nakasaki H and Makuuchi H: Correlation between occult neoplastic cells in the lymph node sinuses and recurrence in patients with Dukes' C colorectal cancer. Oncol Rep 10: 1165-1169, 2003.

9. Mukai M, Sato S, Komatsu N, Nishida T, Shiba K, Ito I, Nakasaki $\mathrm{H}$ and Makuuchi $\mathrm{H}$ : Correlation between occult neoplastic cells in the lymph node sinuses and recurrence in patients with curatively resected Dukes' B colorectal cancer. Oncol Rep 10: 1177-1181, 2003.

10. Mukai M, Sato S, Nishida T, Komatsu N, Shiba K, Nakasaki H and Makuuchi $\mathrm{H}$ : Selection criteria for high risk and low risk groups of recurrence and metastasis in patients with primary colorectal cancer. Oncol Rep 10: 1753-1758, 2003.

11. Mukai M, Sato S, Nakasaki H, Saito Y, Nishiumi N, Iwasaki M, Tokuda Y, Ogoshi K, Inoue H and Makuuchi H: Occult neoplastic cells in the lymph node sinuses and recurrence of primary breast, lung, esophageal and gastric cancer. Oncol Rep 11: 81-84, 2004

12. Mukai M, Sato S, Komatsu N, Kimura T, Ninomiya H, Nakasaki H, Ogoshi K and Makuuchi M: Accuracy of criteria for predicting the recurrence and metastasis of stage I and II gastric cancer without lymph node metastasis. Oncol Rep 12: 59-62, 2004.

13. Mukai M, Sato S, Komatsu N, Kimura T, Ninomiya H, Nakasaki H, Ogoshi K and Makuuchi H: Accuracy of criteria for predicting recurrence and metastasis in stage II and III gastric cancer with lymph node metastasis. Oncol Rep 12: 63-66, 2004.

14. Mukai M, Sato S, Komatsu N, Kimura T, Ninomiya H, Nakasaki H, Ogoshi K and Makuuchi H: Predicting the recurrence/metastasis of stage II and III breast cancer with lymph node metastasis. Oncol Rep 12: 303-306, 2004.

15. Mukai M, Sato S, Komatsu N, Kimura T, Ninomiya H, Nakasaki H, Ogoshi K and Makuuchi H: Predicting the recurrence/metastasis of stage I and II breast cancer without lymph node metastasis. Oncol Rep 12: 745-748, 2004.

16. Mukai M, Sato S, Tajima T, Kimura T, Komatsu N, Ninomiya H, Nakasaki H, Ogoshi K and Makuuchi H: Predicting recurrence and metastasis of stage II/Dukes' B colorectal cancer without lymph node metastasis. Oncol Rep 12: 1127-1130, 2004.

17. Mukai M, Sato S, Tajima T, Kimura T, Komatsu N, Ninomiya H, Nakasaki H, Ogoshi K and Makuuchi H: Predicting recurrence and metastasis of stage III/Dukes' C colorectal cancer with lymph node metastasis. Oncol Rep 12: 1301-1304, 2004.

18. Mukai M, Sato S, Tajima T, Kimura T, Komatsu N, Ninomiya H, Nakasaki H, Ogoshi K and Makuuchi H: Predicting recurrence and metastasis of Dukes' A primary colorectal cancer with or without proper muscle invasion. Oncol Rep 12: 1305-1308, 2004.

19. Tajima T, Mukai M, Sato S, Wakui K, Ninomiya H, Komatsu N, Nakasaki $\mathrm{H}$ and Makuuchi $\mathrm{H}$ : Predicting recurrence and metastasis of primary esophageal cancer with or without lymph node metastasis. Oncol Rep 15: 809-814, 2006. 
20. Mukai M: Occult neoplastic cells and malignant microaggregates in lymph node sinuses: Review and hypothesis. Oncol Rep 14: 173-175, 2005.

21. General Rules for Clinical and Pathological Studies on Cancer of the Colon, Rectum and Anus. Japanese Society for Cancer of the Colon and Rectum. 7th edition, Kanehara \& Co., Ltd., Tokyo, 2006.

22. TNM Classification of Malignant Tumors. 6th edition, John Wiley \& Sons, Inc., NY, 2002.

23. Poon MA, O'Connell MJ, Wieand HS, Krook JE, Gerstner JB, Tschetter LK, Levitt R, Kardinal CG and Mailliard JA: Biochemical modulation of fluorouracil with leucovorin: confirmatory evidence of improved therapeutic efficacy in advanced colorectal cancer. J Clin Oncol 9: 1967-1972, 1991.

24. Petrelli N, Douglass HO Jr, Herrera L, Russell D, Stablein DM, Bruckner HW, Mayer RJ, Schinella R, Green MD, Muggia FM, Megibow A, Greenwald ES, Bukowski RM, Harris J, Levin B, Gaynor E, Loutfi A, Kalser MH, Barkin JS, Benedetto P, Woolley PV, Nauta R, Weaver DW and Leichman LP for the gastrointestinal tumor study group: The moduration of fluorouracil with leucovorin in metastatic colorectal carcinoma: A prospective randomized phase III trial. J Clin Oncol 7: 1419-1426, 1989.

25. Berger SH and Hakala MT: Relationship of dUMP and free FdUMP pools to inhibition of thymidylate synthase by 5 fluorouracil. Mol Pharmacol 25: 303-309, 1984.

26. Okabe H, Tsujimoto $H$ and Fukushima M: Preparation of the antibodies against recombinant human thymidylate synthase for the detection of its intratumoral levels and application to sensitivity-study of 5-fluorouracil. Oncol Rep 4: 685-690, 1997.

27. Douillard JY, Cunningham D, Roth AD, Navarro M, James RD, Karasek P, Jandik P, Iveson T, Carmichael J, Alaki M, Gruia G, Awad L and Rougier P: Irinotecan combined with fluorouracil compared with fluorouracil alone as first-line treatment for metastatic colorectal cancer: a multicentre randomized trial. Lancet 355: 1041-1047, 2000.

28. Saltz LB, Cox JV, Blanke C, Rosen LS, Fehrenbacher L, Moore MJ, Maroun JA, Ackland SP, Locker PK, Pirotta N, Elfring GL and Miller L for the Irinotecan study group: Irinotecan plus fluorouracil and leucovorin for metastatic colorectal cancer. N Engl J Med 343: 905-914, 2000.
29. Tournigand C, Achille TAE, Lledo G, Flesh M, Couteau C, Quinaux DM-ME, Buyse M, Ganem G, Landi B, Colin P, Louvet $\mathrm{C}$ and De Gramont A: FOLFIRI followed by FOLFOX 6 or the reverse sequence in advanced colorectal cancer: A randomized GERCOR study. J Clin Oncol 22: 229-237, 2004.

30. Colucci G, Gebbia V, Paoletti G, Giuliani F, Caruso M, Gebbia N, Cartenì G, Agostara B, Pezzella G, Manzione L, Borsellino N, Misino A, Romito S, Durini E, Cordio S, Seri MD, Lopez M and Maiello E: Phase III randomized trial of FOLFIRI versus FOLFOX 4 in the treatment of advanced colorectal cancer: A multicenter study of Gruppo Oncologico Dell'Italia Meridionale. J Clin Oncol 23: 4866-4875, 2005.

31. Kemeny N, Huang Y, Cohen AM, Shi W, Conti JA, Brennan MF, Bertino JR, Turnbull ADM, Sullivan D, Stockman J, Blumgart LH and Fong Y: Hepatic arterial infusion of chemotherapy after resection of hepatic metastases from colorectal cancer. N Eng J Med 341: 2039-2048, 1999.

32. Mukai M, Sato S, Ninomiya H, Wakui K, Komatsu N, Tsuchiya K, Nakasaki H and Makuuchi H: Recurrence and 5-FU sensitivity of stage III/Dukes' C colorectal cancer with occult neoplastic cells in lymph node sinuses. Oncol Rep 14: 1165-1169, 2005.

33. Mukai M, Sato S, Ninomiya H, Wakui K, Komatsu N, Tsuchiya K, Nakasaki H and Makuuchi H: Recurrence and 5-FU sensitivity of stage II/Dukes' B colorectal cancer with occult neoplastic cells in lymph node sinuses. Oncol Rep 14: 1171-1176, 2005.

34. Mukai M, Sato S, Ninomiya H, Wakui K, Komatsu N, Tsuchiya K, Nakasaki H and Makuuchi H: Recurrence and 5-FU sensitivity of node-positive stage II/III gastric cancer with occult neoplastic cells in lymph node sinuses. Oncol Rep 14: $1505-1510,2005$

35. Feinstein AR, Sosin DM and Wells CK: The Will Rogers phenomenon: Stage migration and new techniques as a source of misleading statistics for survival in cancer. $N$ Engl J Med 312: 1604-1608, 1985.

36. Bunt AMG, Hermans J, Smit VTHBM, van de Velde CJH, Fleuren GL and Bruijn JA: Surgical/pathologic stage migration confounds comparisons of gastric cancer survival rates between Japan and Western countries. J Clin Oncol 13: 19-25, 1995. 